\title{
Microstructure Evolution and Failure Modes of a Resistance Spot Welded TWIP Steel
}

\author{
Tiago Colombo ${ }^{1}$ (D), Guilherme dos Santos ${ }^{1}$, Pedro Teruel ${ }^{1}$, Jorge Otubo ${ }^{1}$, Alfredo Faria ${ }^{1}$ \\ ${ }^{1}$ Instituto Tecnológico de Aeronáutica - ITA, Departamento de Engenharia Mecânica, São José dos Campos, SP, Brasil.
}

Received: 12 Oct., 2018

Accepted: 21 Dec., 2018

E-mails: colombo@ita.br (TC); guilherme@ita.br(GS); teruel@ita.br(PT); jotubo@ita.br(JO); arfaria@ita.br(AF)
Abstract: This study discusses the microstructure, quasi-static mechanical strength and failure modes of TWIP steel weld spots. Weld spots were produced by varying the main resistance spot welding parameters: welding current, welding time and electrode compression force. All the samples showed a remarkable material hardness mismatch between the fusion zone, the heat affected zone and the base material, as evidenced by microindentation maps. Hardness at the fusion zone is lower than that of heat-affected zone and base metal, which facilitates interfacial failure mode during tensile-shear tests. However, high heat inputs promoted the failure mode changes to partial interfacial mode and then to pullout mode during tensile-shear tests as confirmed by Scanning Electron Micrographs. These changes in failure mode were accompanied by a notable increase in tensile-shear strength and energy absorption capability.

Key-words: TWIP steel; Failure modes; HAZ hardening; Tensile-shear strength.

\section{Evolução Microestrutural e Modos de Falha de um Aço TWIP Soldado a Ponto por Resistência}

Resumo: Este estudo aborda a microestrutura, ensaio de tração quasi-estático e modos de falha de um aço TWIP soldado a ponto por resistência. Pontos de solda foram produzidos variando os principais parâmetros de soldagem: corrente de soldagem, tempo de soldagem, e força do eletrodo. Para todas as amostras, as diferenças de dureza, observadas via mapas de dureza por microindentação, entre a zona fundida, a zona termicamente afetada e o metal-base foram consideravelmente elevadas. A dureza da zona fundida é menor que esta da ZTA e do metal-base, facilitando falhas interfaciais durante ensaio de tração-cisalhamento. Porém, elevado aporte térmico acarreta na mudança do modo de falha para parcialmente interfacial e arrancamento, como confirmado via microscopia eletrônica de varredura. Esta mudança é também acompanhada por um notável aumento na resistência em tração-cisalhamento e capacidade de absorção de energia.

Palavras-chave: Aço TWIP; Modos de falha; Endurecimento da ZTA; Resistência a tração-cisalhamento.

\section{Introduction}

Twinning-Induced Plasticity (TWIP) steels have gained increasing importance in the transportation industry due to their combination of very high yield and ultimate tensile strength with elevated ductility, yet keeping cold formability. Such properties are desirable to increase strength and decrease weight of critical components by using thinner and formable steel sheets. Due to their technological importance, much effort has been applied recently to understand the microstructure evolution during plastic deformation of TWIP steels. Some worthy investigations can be found from the studies of Beladi et al. [1], Kim et al. [2], Chin et al. [3] and De Cooman et al. [4].

Following the sheet forming processes, individual components in transportation industry are usually assembled by means of joining processes. Among the joining processes applied in automotive body-in-white manufacturing, resistance spot welding (RSW) is considered the dominant one, mainly due to its low-cost, ease of automation and robustness [5]. The quality of the weld spots has significant influence on the structural integrity of assembled components and, in a larger perspective, on the performance of the vehicle. An adequate definition of RSW parameters has, therefore, great importance, since they may have a direct impact on the quality of the weldment. Despite the importance of the welding processes on the quality and safety of the assembled components, little has been published on the effects of RSW parameters on the quality of TWIP weld spots. 
Saha et al. [6] showed that spot-welded 18\%wt, Mn TWIP steel exhibited only interfacial failure (IF) mode, with shear deformation along the centerline of the weld nugget. In fact, Pouranvari and Marashi [7] and Rao et al. [8] state that one of the main concerns regarding the use of AHSS in RSW process is the tendency to fail in interfacial failure mode, in which the crack propagates through the fusion zone of the weldment, especially when loaded in tensile-shear loading condition. Interfacial failure mode is not desirable for automotive applications, as it is usually associated with low plastic deformation and low load bearing capacity.

As recently stated by Rao et al. [8], the change between the interfacial failure mode to pullout failure (PF) mode, in which there is an increase in tensile shear strength, plastic deformation and load bearing capacity, mainly depends upon the size of the weld nugget. Therefore, changes in welding parameters in order to promote an increase in weld nugget size could result in pullout failure mode. Additionally, variations in chemical composition of TWIP steels and different combinations of welding parameters could lead to different results. Razmpoosh et al. [9] studied a spot-welded 31\%wt. Mn TWIP steel grade. They reported a spot weld fusion zone (FZ) harder than the heat affected zone (HAZ), which facilitates the occurrence of ductile pullout failure (PF) mode, differing from the observed by Saha et al. [6]. Russo Spena et al. [10] and Kazdal Zeytin et al. [11] on the other hand, observed softening in both HAZ and FZ when compared to the BM, indicating that softening mechanisms take part in the HAZ. The cited works, however, agree in that there is a distribution of mechanical properties throughout the weldment and such distribution in sensible to the welding parameters. Therefore, according to Pouranvari and Marashi [7], Rao et al. [8] and Razmpoosh et al. [9], one may conclude that variations on welding parameters may impact the failure modes and so the mechanical properties of the weld spots.

The aforementioned few publications on spot-welded TWIP steels provide meaningful contributions to the state of the art regarding the microstructure evolution and mechanical properties of the spot-welded TWIP steels. Nonetheless, they do not yet fully satisfy the gap on the subject, as investigations covering a larger range of welding parameters and their impact on mechanical properties of the weld spots were not performed. In the light of the above, the present study emphasis the correlation between welding parameters, microstructure and mechanical properties of TWIP steel weld spots.

\section{Materials and Methods}

Experimental investigations were conducted with uncoated $0.8 \mathrm{~mm}$ thick Fe-Mn-C-Si-Al austenitic TWIP980 steel sheets with the chemical composition shown in Table 1. The microstructure at room temperature is fully austenitic, with an average grain size of $2.5 \mu \mathrm{m}$.

Table 1. Chemical composition of the investigated steel (wt. \%).

\begin{tabular}{ccccccccc}
\hline $\mathbf{C}$ & Mn & Al & Ti & Cr & Mo & Si & Ni & Fe \\
0.75 & 16.4 & 1.91 & 0.10 & 0.72 & 0.26 & 0.05 & 0.03 & Bal. \\
\hline
\end{tabular}

Weldings were conducted using a Düring CB 150 kvA spot welding machine, a Harms \& Wende Ratia 73 welding panel and a copper electrode with a face diameter of $6.0 \mathrm{~mm}$ with constant water cooling flow rate of $6 \mathrm{l} . \mathrm{min}^{-1}$. The steel sheets were water jet cut in $50 \times 30 \mathrm{~mm}$ dimensions and then welded by RSW linear overlapping positioned. The welding current was varied from 6 to $8 \mathrm{kA}$ with a step of $1 \mathrm{kA}$. The electrode compression force varied from $2 \mathrm{kN}$ to $4 \mathrm{kN}$, with a step of $1 \mathrm{kN}$. Welding time varied from 8 cycles to 16 cycles, with a step of 4 cycles. Squeeze time and holding time was 32 and 12 cycles, respectively.

Quasi-static tensile-shear tests were performed using an electromechanical Instron Universal Testing Machine at a cross head speed of $10 \mathrm{~mm} \cdot \mathrm{min}^{-1}$. The mechanical strength of the weld spots was investigated and compared to each welding current interval by analyzing the tensile-shear load vs. displacement curves obtained from tensile-shear tests up to maximum load. The amount of energy absorption was determined by numerical integration of the area under the tensile-shear load vs. displacement curves. The effect of the welding parameters on the average tensile-shear strength was statistically verified by comparisons between pairs of values with a $95 \%$ confidence level Tukey test. 
Conventional metallographic procedures and optical microscopy observations were conducted to reveal the metallurgical microstructures along the Base Metal (BM), Heat Affected Zone (HAZ) and Fusion Zone (FZ). Vickers hardness maps were carried out on the polished samples under an indentation load of $1 \mathrm{~N}$ and grid spacing $62.5 \mu \mathrm{m}$, using a Emcotest hardness tester. The fractured surfaces of the tensile tested samples were investigated by scanning electron microscopy (SEM) using a TESCAN VEGA 3 XMU microscope in the secondary electron imaging mode.

\section{Results and Discussions}

\subsection{Microstructural characterization of the weld spots}

Saha et al. [6] and Razmpoosh et al. [9] reported that the as-welded grain morphology of spot-welded TWIP steels consist of columnar dendritic grain structure at the FZ and equiaxed grains at the HAZ. Similar findings are obtained by examining the weld cross sections at different regions of the present TWIP steel marked in Figure 1a. The solidification microstructure of the FZ (Figure 1b) consists of a preferentially columnar dendritic grain structure, with some amount of equiaxed dendrites also present. The dendritic grains grow preferentially in the thermal gradient direction, normal to the solid/liquid interface.

The grain structure at the transition between the FZ and the HAZ, marked as B in Figure $1 \mathrm{a}$, is shown in Figure $1 \mathrm{c}$. It is possible to observe a region of small equiaxed grains adjacent to the $F Z$, named PMZ (partially molten zone), followed by a region of coarser grains, named CGHAZ (coarse-grained HAZ). According to Saha et al. [12], the
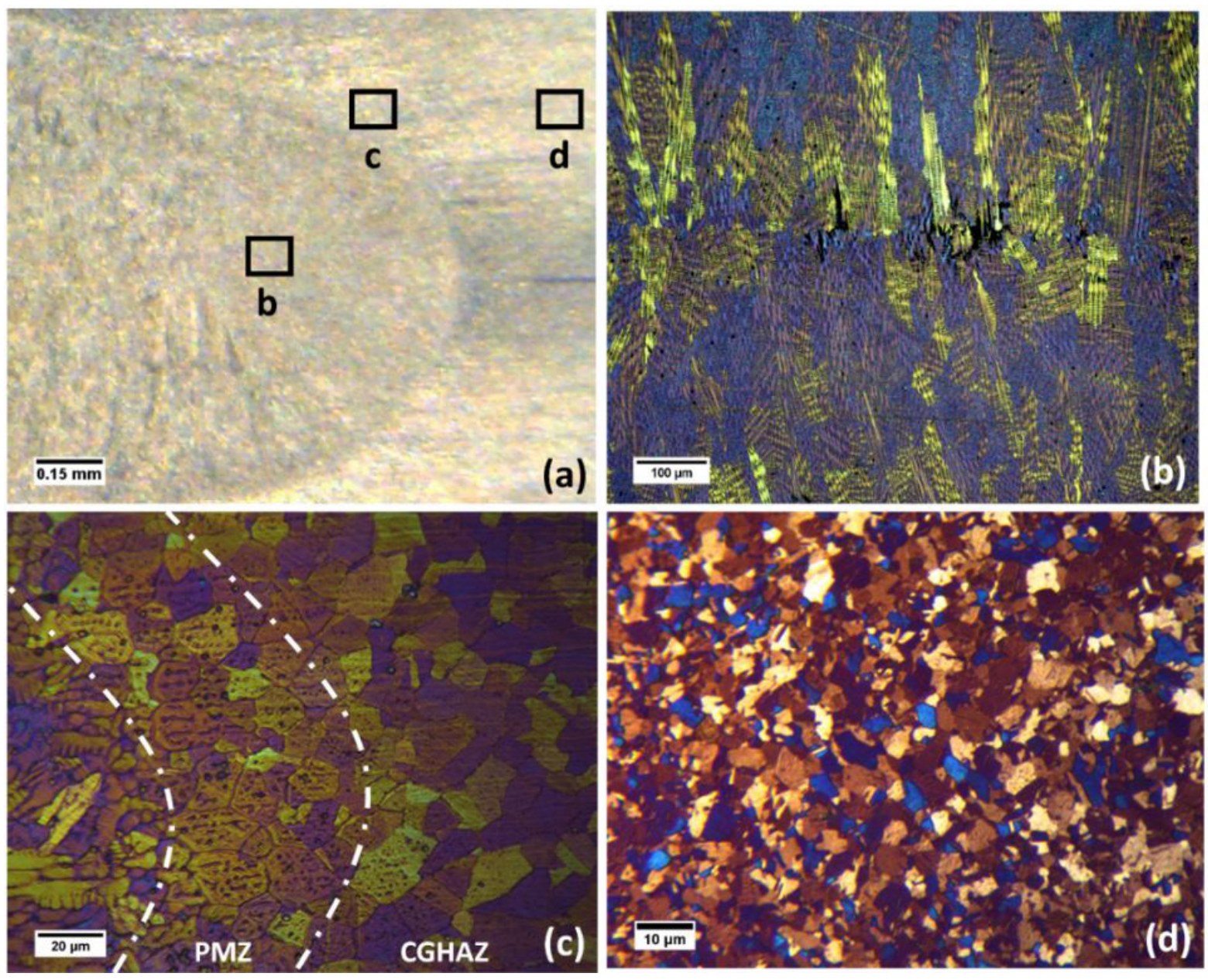

Figure 1. Optical observations of the weld spot using 6 kA: (a) Nugget, (b) fusion zone, (c) partially molten zone (PMZ) and coarse-grained heat affected zone (CGHAZ) and (d) base material. 
PMZ experiences temperatures between the solidus and liquidus temperatures of the alloy, resulting in incomplete fusion of the BM at this region. The existence of a PMZ is usually associated with the appearance of liquation cracks, which nucleates at the PMZ and propagates through the HAZ towards the BM. Saha et al. [6,12] attribute it to the segregation of solutes $\mathrm{C}$ and $\mathrm{Mn}$ and other alloy elements and impurities, especially Ti, Ni, Si, S, P. However, liquation cracks at the PMZ were not identified in the TWIP steel grade investigated in this study.

When the heat input is increased, the evolution of grain structure is similar (Figure 2). The material at the CGHAZ (Figure 1c and Figure $2 \mathrm{~b}$ ) is exposed to a temperature below the liquidus temperature of the alloy but well above Ac3 for a considerable period of time. As observed in Figure 1 and Figure 2, it facilitates the growth of austenite grains along a narrow region adjacent to the fusion zone.

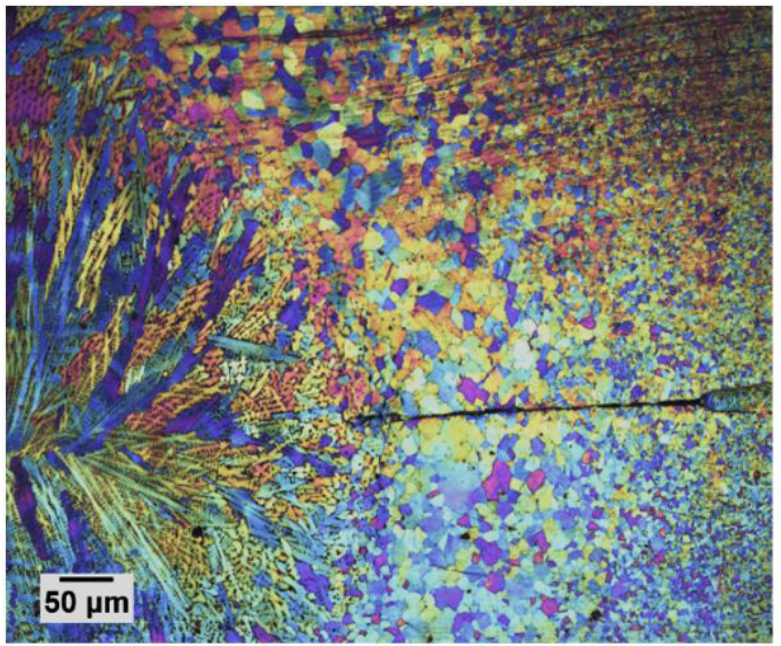

(a)

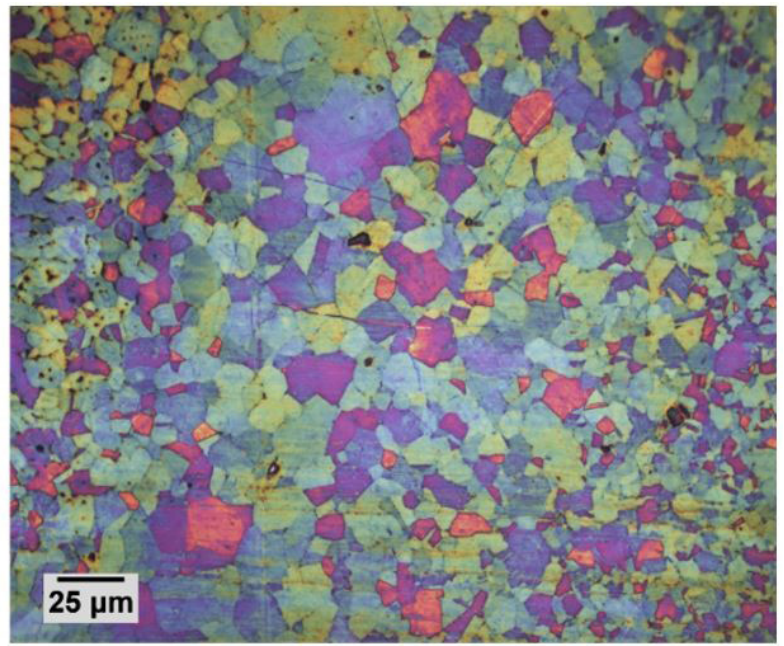

(b)

Figure 2. Optical observations of the weld spot using a welding current of $8 \mathrm{kA}$ : (a) overview of the weldment and (b) localized grain growth at the HAZ adjacent to the FZ.

\subsection{Vickers hardness distributions}

Vickers hardness maps of half of the weld spots cross section for different welding currents are shown in Figure 3. It is observable that the hardness distribution along the FZ is remarkably dispersed. As seen from Figure 1b, the grain structure consists of columnar grains of different sizes and also some equiaxed grains. Furthermore, Russo Spena et al. [10] and Saha et al. [12] also reported that the FZ is prone to segregation of chemical elements, especially Mn. Such heterogeneous structure, combined to the presence of defects such as pores and voids, lead to a heterogeneous distribution of mechanical properties, as evidenced by the Vickers hardness maps in Figure 3.

For all samples, a gradual increase in hardness is observed over the HAZ towards the FZ. A softer region at the transition between the $\mathrm{FZ}$ and the HAZ is observed, which corresponds to the material softening promoted by the coarser grain region evidenced in Figure 2. The hardness then increases towards the base material. It can be seen that higher welding currents did not promote appreciable effect on the magnitude of the hardness values, but widens the material fraction corresponding to the HAZ (yellow region in Figure 3). It is in agreement to Kazdal Zeytin et al. [11], which states that increments in the heat input (welding current) promote increase in the FZ zone, thus increasing the material fractions that are affected by the thermomechanical cycle.

It is worth to note that the highest values of hardness are found near the surface, closer to the material fractions in contact to the electrodes. By means of stress distribution simulation of the RSW process, Ashiri et al. [13] pointed out a tensile stress built up right beside the electrode contact area, which coincides with the region of highest hardness described in this paper. The lowest values are found at the centerline of the FZ, which is the last region to solidify, also coinciding to the region of a higher amount of defects found by Saha et al. [6]. 


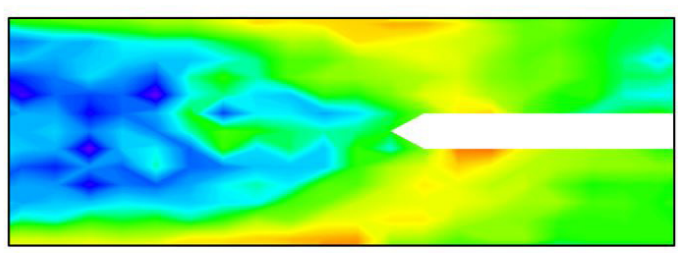

(a) $\mathrm{I}=6 \mathrm{kA}, \mathrm{F}=2 \mathrm{kN}, \mathrm{t}=8$ cycles

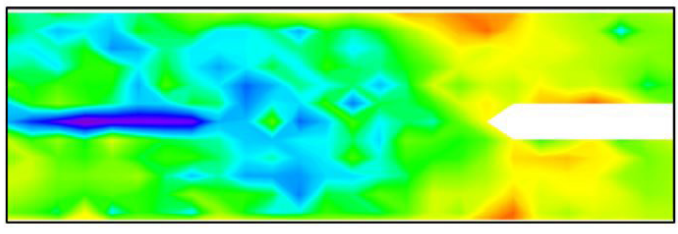

(b) I $=8 \mathrm{kA}, \mathrm{F}=2 \mathrm{kN}, \mathrm{t}=8$ cycles

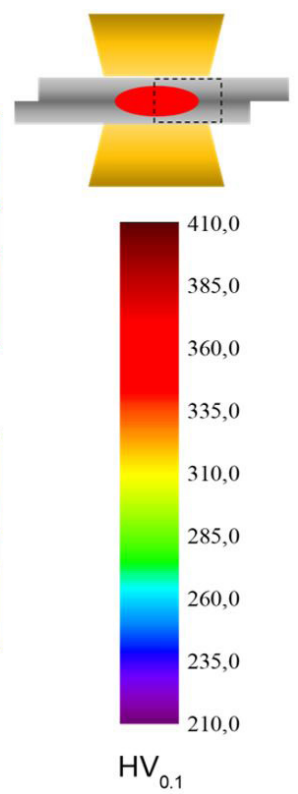

Figure 3. Vickers hardness maps of weld spots with: (a) $6 \mathrm{kA}$ and (b) $8 \mathrm{kA}$. Electrode compression force: $2 \mathrm{kN}$ and welding time: 8 cycles.

Differently than the observed by Spena et al. [10] and Zeytin et al. [11], the hardness maps in Figure 3 evidence a HAZ slightly harder than both FZ and BM. This difference can be attributed to many factors, especially the difference in chemical composition between the investigated alloys. Spena et al. [10] investigated a TWIP steel with 0.51 wt.\% C and $22.4 \mathrm{wt} \% \mathrm{Mn}$, while Zeytin et al. [11] investigated a TWIP steel with considerably lower C content (0.024\%wt.) and higher Mn content (32 wt.\%). Therefore, different softening and hardening mechanisms may take part for different alloys, especially when one observes the phenomena involved in a RSW cycle: In terms of microstructure evolution, the thermomechanical loads induced by the RSW parameters may promote material transformations that can be approximately compared to those involved during a hot upsetting process, although in the latter there is no change of physical state. The compression force applied by the electrodes may promote work hardening, as an increase in dislocation density leads to an increase in stress necessary for further plastic deformation. It is especially true for TWIP steels, as these steels exhibit high work hardening coefficient, in the order of $0.5[4,14]$. The high work hardening is due to the existence of twinning deformation mode, which act as another strengthening mechanism. It can lead to a considerable increase in hardness, mainly at the regions close to the electrode-sheet interfaces. Therefore, if softening mechanisms that reduces the density of crystalline defects (i.e., recovery or recrystallization) does not predominate over the work hardening imposed by the thermomechanical loads during the welding cycle, it is plausible to assume that the work hardening along the HAZ should be manifested as an increase in hardness when compared to the base material, as observed in the hardness maps in Figure 3 [15]. Deeper investigations are needed for a better comprehension on the microstructure evolution along the HAZ during the welding cycle, which is not the aim of the present study.

\subsection{Failure modes and fractography}

Figure 4 shows a macrograph and a scanning-electronic micrograph (SEM) of the failure modes observed for welding currents up to $6 \mathrm{kA}$. The samples exhibited the typical brittle interfacial failure (IF) mode. This failure mode is associated with a crack propagation through the weld nugget (Figure 4a). It is possible to observe the flatness of the surface, indicating little plastic deformation, combined with the presence of torn bands visible by SEM, which are associated to a quasi-cleavage fracture, typical of a brittle fracture mechanism (Figure 4b) [16,17].

The weld spots produced with welding currents of $7 \mathrm{kA}$ exhibit the partial interfacial failure (PIF) mode (Figure 5). In this failure mode, the crack initially propagates through the FZ at approximately 45 degrees of the surface plane and then redirects through the thickness direction [17,18]. Figure 5a shows the macrograph of a weld 
spot which failed under PIF mode. The SEM micrograph of the flat part of the fracture surface, marked as Box A, is enlarged in Figure $5 \mathrm{~b}$. It is possible to observe depressions caused by the propagating crack and large shrinkage voids. An insufficient molten metal volume, which may be caused by low heat input and/or molten expulsion, may
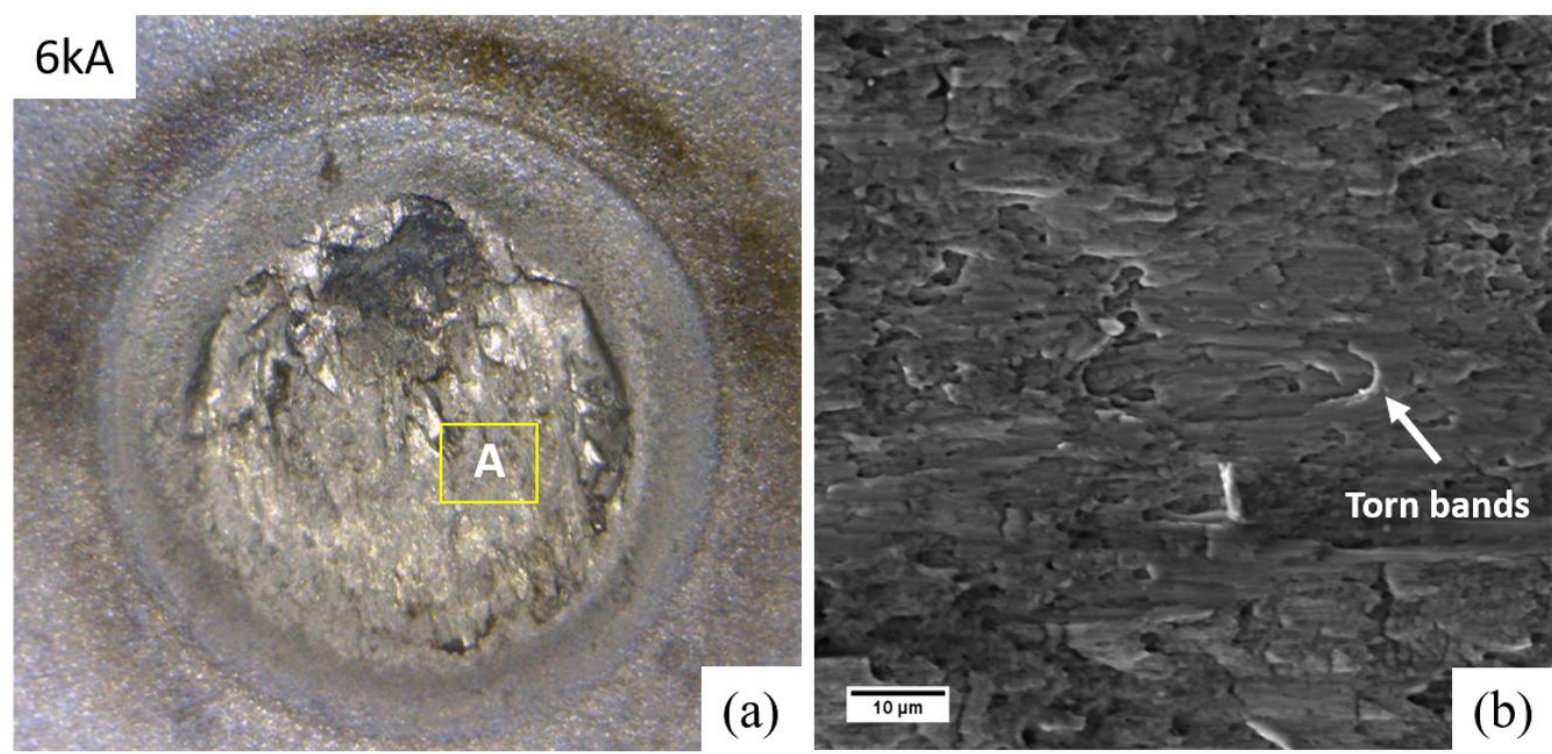

Figure 4. Observations of the fracture surfaces: (a) macrograph evidencing IF mode, I = $6 \mathrm{kA}$, (b) SEM micrograph of the region marked as box $A$. Welding time $=8$ cycles and electrode force $=2 \mathrm{kN}$.
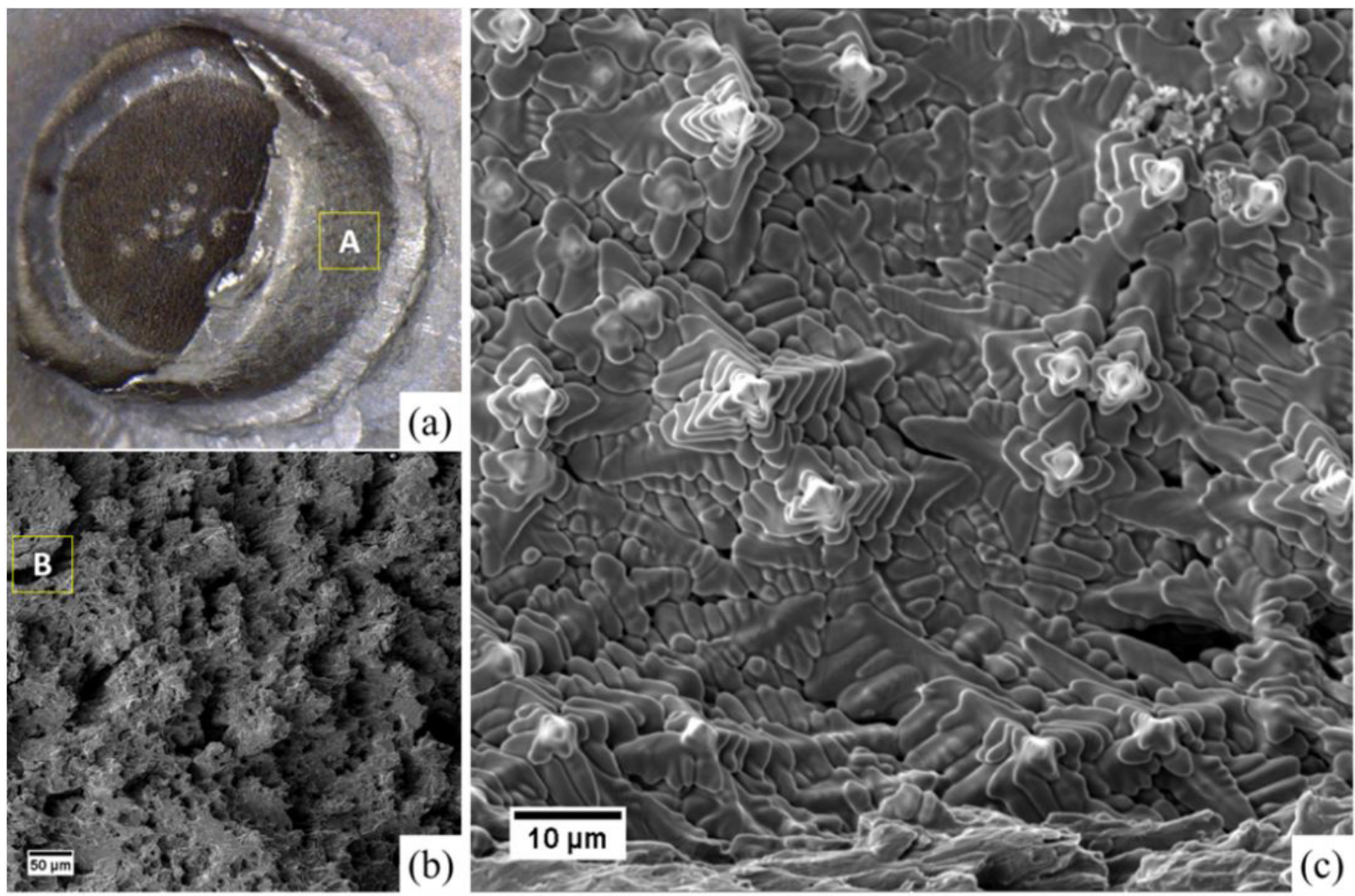

Figure 5. Observations of the fracture surface, I = $7 \mathrm{kA}$ : (a) macrograph evidencing PIF mode, (b) SEM micrograph of the region marked as box A and (c) SEM micrograph of box B. Welding time $=8$ cycles and electrode force $=2 \mathrm{kN}$. 
cause the formation of shrinkage voids and cracks. When the Box B is enlarged (Figure $5 c$ ), dendrites are visible on the surface of these large voids. These dendrites exhibit the characteristics of free solidification structure, as they consume the last solidifying liquid during cooling. Free solidification structures associated to insufficient molten metal volume may act as facilitating crack nucleation and propagation during mechanical loading, thus providing low mechanical strength for the weld nugget, even if adequate weld nugget size is achieved.

When the welding current is increased to $8 \mathrm{kA}$, the failure of the tensile-shear loaded samples occurs predominantly by the withdrawal of the weld spot from one sheet, preferentially through the HAZ around the weld nugget (Figure 6), accompanied by a higher amount of plastic deformation before complete failure. It characterizes a pullout failure (PF) mode. The weld nugget itself remained intact under mechanical loading, as evidencing in Figure 6a. The SEM micrograph (Figure 6b) of the fractured surface at the failure initiation site (indicated in Figure 6a) evidences microvoids coalescence (dimples) at the HAZ, which is associated with a ductile failure mechanism. It is possible to identify small dimples combined with larger and deeper ones. Razmpoosh et al. [9] have also identified similar fracture surfaces in TWIP steels in their study. Their results indicated that such variation in dimple size may originate from variations in grain size along the HAZ. Such statement is in agreement with the metallographic observations in Figure 2.
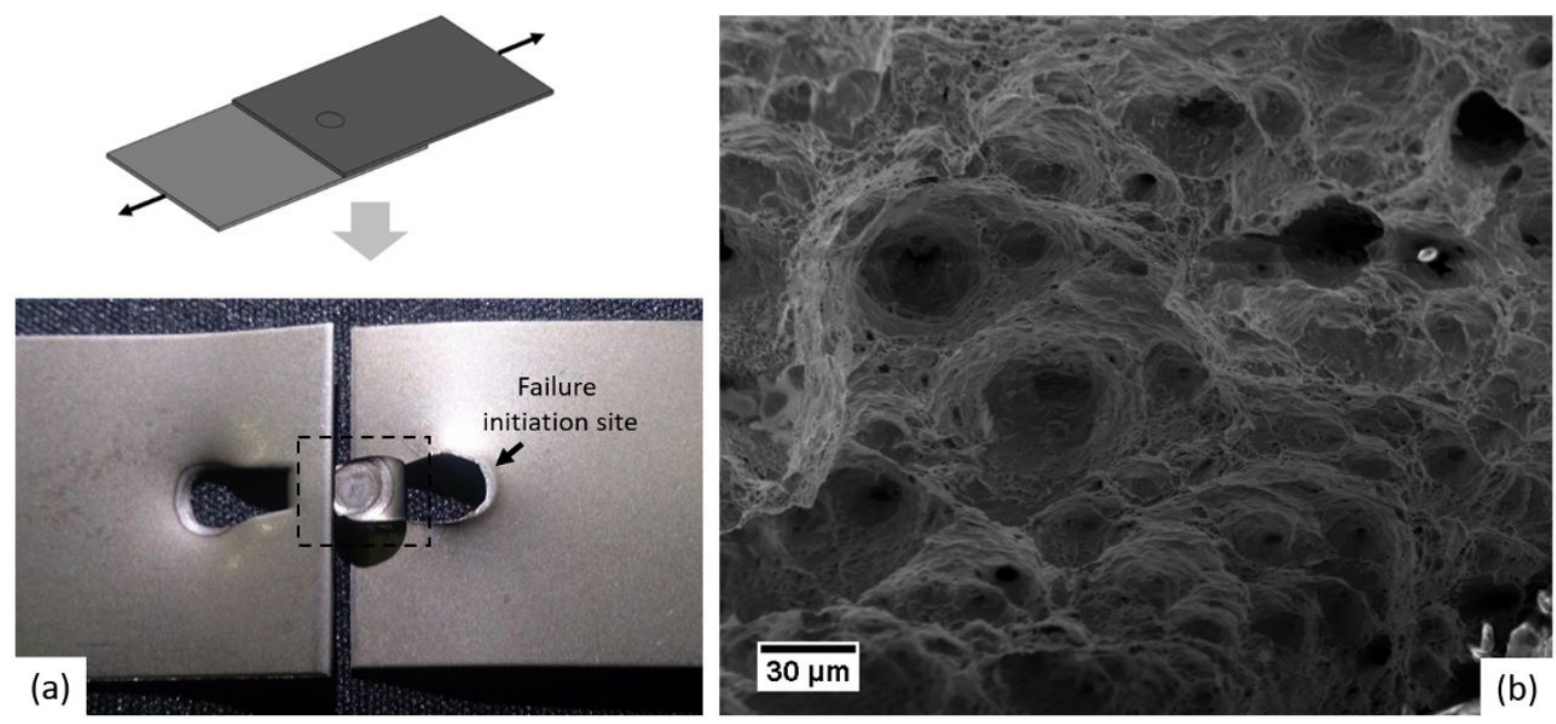

Figure 6. Observations of the fracture surfaces: (a) macrograph evidencing PF mode (top view) and (b) SEM micrograph of the fractured surface at the failure initiation site.

Pouranvari and Marashi [7] stated that both nugget size and hardness ratio between FZ and HAZ most influence the failure mode of RSWs. The larger is the nugget size, the lower the shear stress at the sheet-sheet interface, facilitating the occurrence of Pullout Failure (PF) mode. Hardness, in turn, has a strong influence on the failure mode as the necking during tensile shear loading tends to occur preferentially where hardness is lower. The higher the hardness of the $\mathrm{FZ}$ relative to the hardness of $\mathrm{HAZ}$ or $\mathrm{BM}$, the higher is the chance of PF mode in detriment of IF mode, as it provides a preferential location for necking during the tensile-shear loading [7]. As shown in Figure 3, the FZ hardness of the TWIP steel weld spots is lower than the hardness of BM or HAZ. Based on such statements, it is possible to presume that the increase in nugget size at $8 \mathrm{kA}$ is the driving force to promote the change in failure mode. Although previous studies in literature stated that TWIP steels tend to fail in IF mode, the present results show that it is possible to achieve a favorable failure mode if adequate welding parameters are adjusted.

Figure 7 shows EDS images of the elemental distribution of $\mathrm{Fe}, \mathrm{Mn}, \mathrm{Al}, \mathrm{O}, \mathrm{Si}, \mathrm{Ti}, \mathrm{C}$ and $\mathrm{N}$ taken from the free solidification dendritic surface shown in Figure $5 \mathrm{c}$. It is possible to observe high concentrations of $\mathrm{Al}$ and $\mathrm{O}$ in specific regions, indicating the presence of aluminum oxide. Al segregation may be a concern as Al has two main roles in the chemical composition of TWIP steels: suppress cementite precipitation by reducing the activity and 

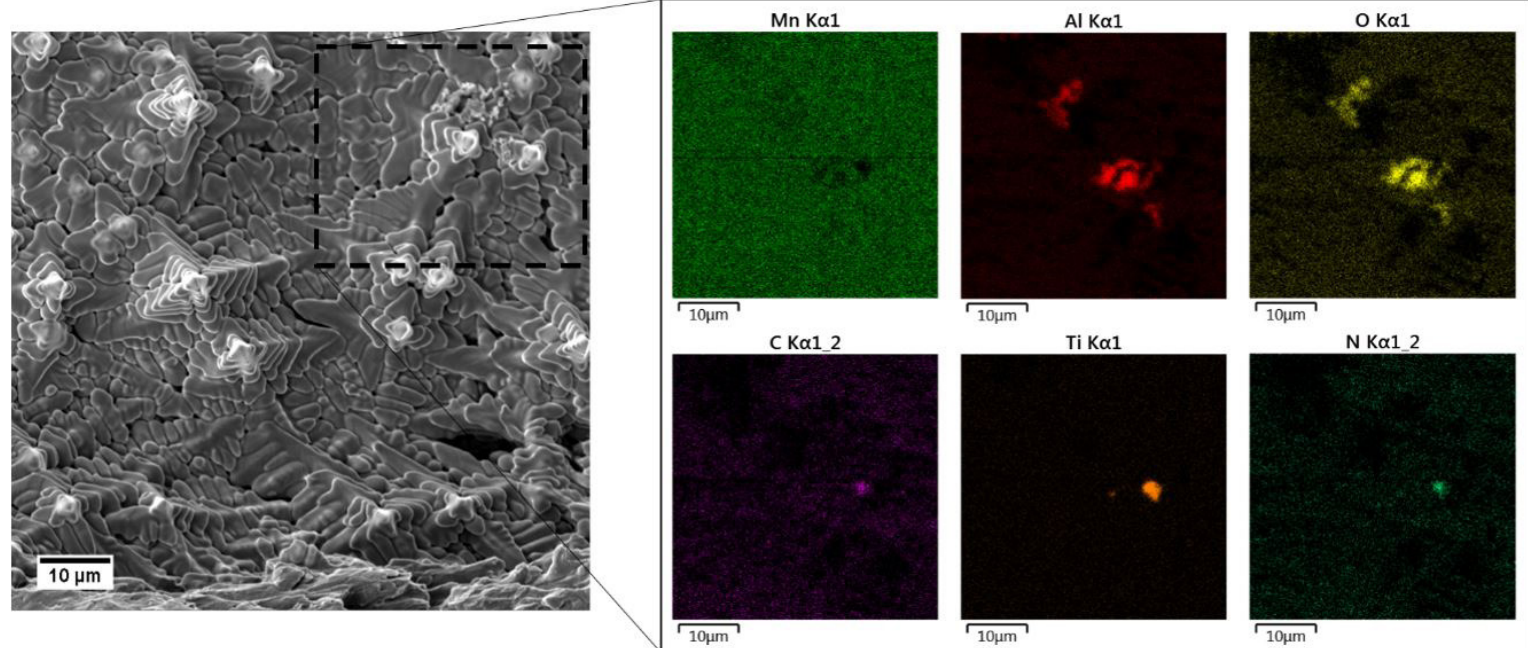

Figure 7. EDS maps for elements $\mathrm{Mn}, \mathrm{Al}, \mathrm{O}, \mathrm{C}, \mathrm{Ti}$, and $\mathrm{N}$ at the free solidification surface.

diffusivity of $\mathrm{C}$ in austenite and suppress strain-induced martensitic transformation by increasing the material stacking fault energy (SFE) $[2,19]$. Therefore, Al segregation may decrease the austenite stability in the adjacent regions, facilitating undesirable phase transformations. No Mn segregation was identified in the free solidification surface, possibly due to the very high cooling rates associated with RSW process, which hinders Mn diffusion.

\subsection{Tensile-shear tests}

The quasi-static tensile-shear tests were performed to quantify the sensibility of the load bearing capacity and energy absorption of the weld spots to the welding parameters. The tensile-shear vs. displacement curves were correlated with the respective dominant failure modes. The solid lines indicate the average values and the contours represent the respective standard deviations.

Figure 8 shows the representative tensile-shear vs. displacement curves for different welding current values, keeping constant the electrode compression force $(2 \mathrm{kN})$ and the welding time ( 8 cycles). It is possible to observe an increase in the average tensile-shear strength (TSS) when increasing the heat input applied. For a welding current of $6 \mathrm{kA}$ (Figure 8a), the corresponding average TSS is $7.3 \mathrm{kN}$. For a welding current of 7 kA (Figure 8b), the TSS increases to $7.9 \mathrm{kA}$ and then to $8.2 \mathrm{kA}$ when the welding current is raised to $8 \mathrm{kA}$ (Figure $8 \mathrm{c}$ ). According to Pouranvari and Marashi [7], the mechanical strength of a weld spot is beneficed by higher heat inputs. It is attributed to a larger weld spot size associated to higher welding currents, which facilitates the load bearing capacity when the weld spots are tensile-shear loaded. As seen in Figure 8, these statement also prevails for TWIP steel weld spots.

It is possible to observe from Figure 8 that the standard deviation tends to decrease when increasing the heat input. The contours along the tensile-shear curve for a welding current of $6 \mathrm{kA}$ is higher, meaning that there were samples that withstood tensile-shear load values considerably different than the average values. It can be interpreted as a low mechanical stability for such welding setup, even considering a quasi-static loading. On the other hand, when higher heat inputs are applied, the average load bearing capacity values tend to be accompanied by lower standard deviations. The Tukey test (Figure 8e) shows that the average values of tensile-shear strength for each level of factor welding current are all significantly different from one another with a confidence level of $95 \%$.

The elongation up to the maximum tensile-shear load seems to be not sensible to the welding current. All the load vs displacement curves exhibited an average displacement of $0.92 \mathrm{~mm}$ when the maximum tensile-shear load is reached. However, the samples that fail in PIF mode and PF mode continue to withstand the mechanical load when the maximum load is reached, while the samples that fail in a brittle manner (IF mode) complete fail moments after the maximum tensile-shear load is achieved.

The influence of the welding current on the energy absorption capability of the weld spots is also shown in Figure $8 \mathrm{~d}$. It was obtained by the integration of the area below the tensile-shear vs. displacement curve, up to the 
maximum tensile-shear load. As observed for the TSS, the energy absorption capability also increases with the increase in the heat input. The standard deviation is also lower for higher welding currents, indicating a tendency of stabilization of mechanical properties for higher welding currents, at least for the welding current range applied.

Figure 9 shows the effect of the electrode compression force on the TSS of the weld spots. Although the dominant failure mode shifts from PF to PIF when higher electrode compression forces are applied, the tensile-shear vs. displacement curves for electrode compression force values of $2 \mathrm{kN}$ (Figure 9a) and $3 \mathrm{kN}$ (Figure 9b) are slightly similar in their behaviors, even considering the respective standard deviations. When an electrode compression force of $4 \mathrm{kN}$ is applied (Figure 9c), it is possible to observe a higher dispersion, especially after the point of maximum TS load. Differently than the observed for the welding current, the average quasi-static TSS is less affected by an increase in the electrode compression force. The average TSS values range between 8.1 and $8.2 \mathrm{kN}$. The neglected effect of the electrode compression force on the average TSS is in agreement with the results from the Tukey test
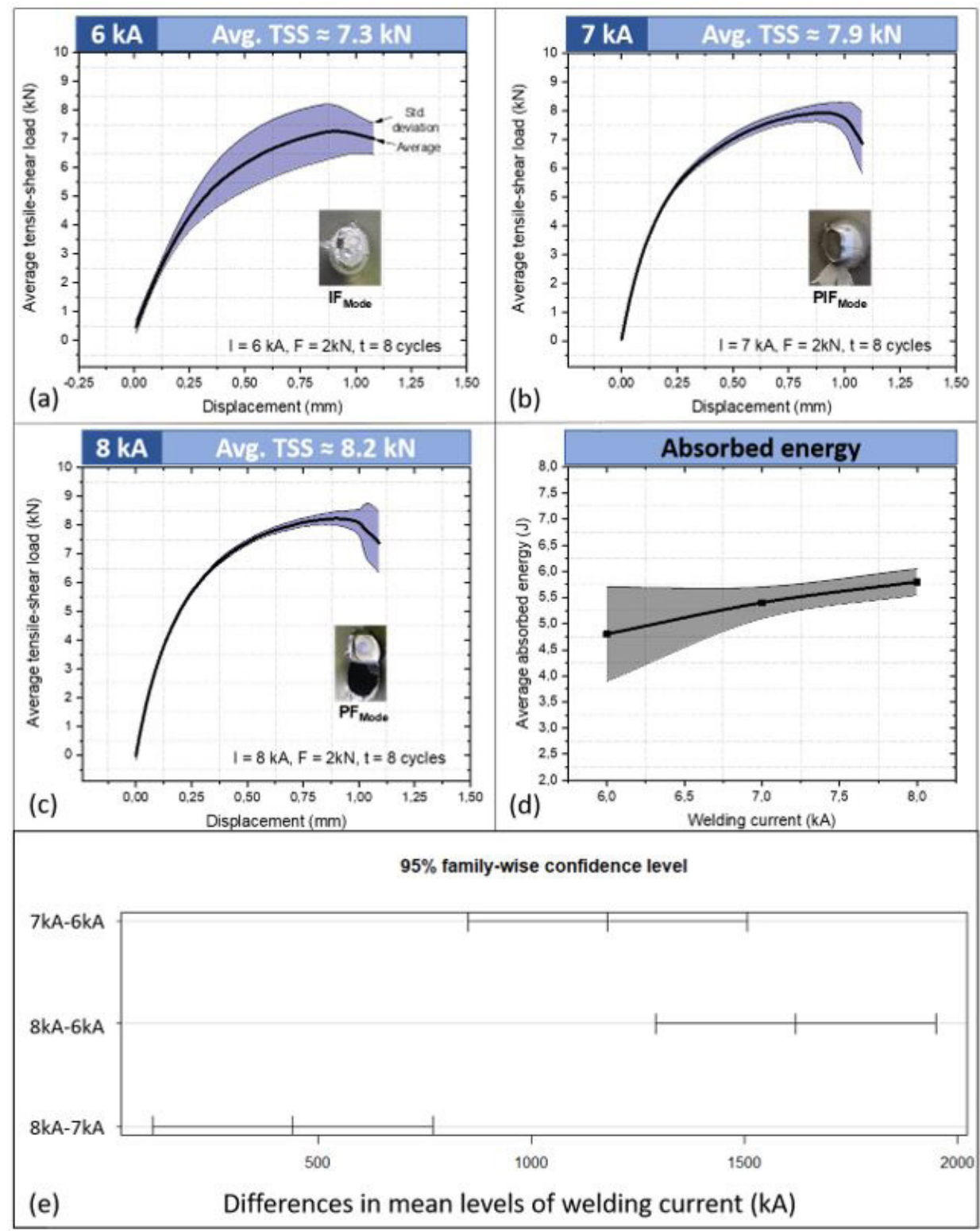

Figure 8. Tensile-shear test results for different welding current values. Welding time (8 cycles) and electrode compression force $(2 \mathrm{kN})$ were kept constant. 
(Figure 9e), that shows that all average values of tensile-shear strength for each electrode compression force level are found to be statistically equivalent within a 95\% confidence level.

The displacement at maximum tensile-shear load exhibits a slightly tendency to decrease with increasing the electrode force, ranging from 0.92 to $0.88 \mathrm{~mm}$ when forces of $2 \mathrm{kN}$ and $4 \mathrm{kN}$ are applied, respectively. The negligible effect of the electrode compression force on mechanical properties of the weld spots produced with $8 \mathrm{kA}$ of welding current is also visible when observing the absorbed energy of the weld spots in Figure $9 \mathrm{~d}$. The values range between 5.4 and $5.7 \mathrm{~J}$. Considering the standard deviation, it can be assumed that the electrode compression force has no significant influence on the energy absorption capability of the weld spots.

To better analyze the effect of the electrode compression force on the mechanical properties of the weld spots under tensile-shear loading, weld spots were produced with a welding current of $7 \mathrm{kA}$ and electrode force values ranging from $2 \mathrm{kN}$ to $4 \mathrm{kN}$. The tensile-shear vs. displacement curves for this dataset are shown in Figure 10.
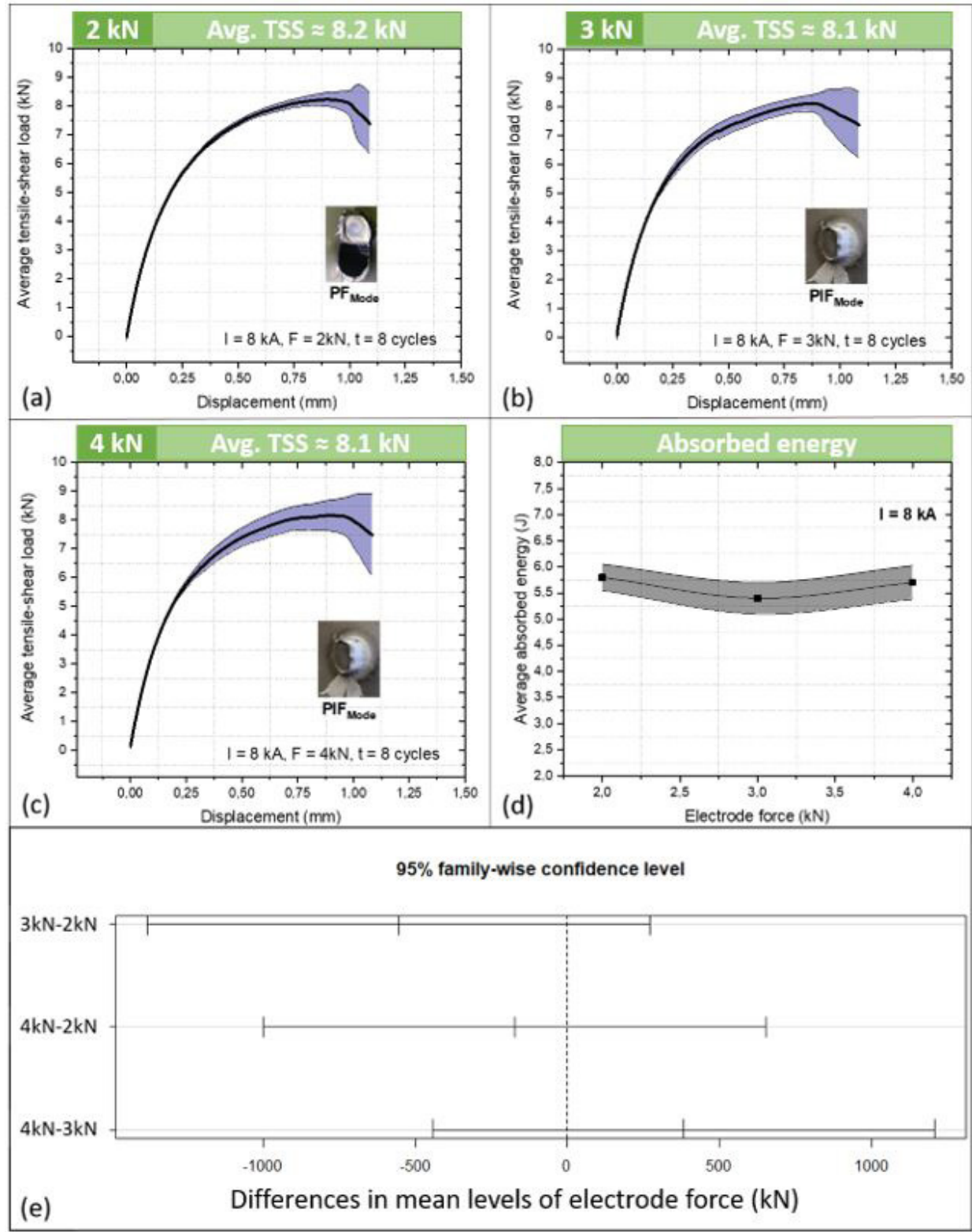

Figure 9. Tensile-shear test results for different electrode compression force values. Welding current ( $8 \mathrm{kA})$ and welding time (8 cycles) were kept constant. 
The influence of the electrode force on the degradation of mechanical properties shows to be more apparent when lower welding currents are applied. Although a change in electrode compression force does not promote a change in the dominant failure mode (PIF mode), it is remarkable the effect on the TSS of the weld spots. The TSS decreases from $7.9 \mathrm{kN}$ to $6.9 \mathrm{kN}$ when the electrode force increase from $2 \mathrm{kN}$ (Figure 10a) to $4 \mathrm{kN}$ (Figure 10c), corresponding to a decrease in TSS of about 13\%. The Tukey test plot (Figure 10e) shows statistical equivalence only between the low $(2 \mathrm{kN})$ and medium $(3 \mathrm{kN})$ levels of the electrode compression force. The high level $(4 \mathrm{kN})$ is significantly different from the other levels.

The ductility of the weld spots, represented by the displacement at the point of maximum tensile-shear load, also decreases when increasing the electrode compression force, considering a welding current of $7 \mathrm{kA}$. For an electrode force of $2 \mathrm{kN}$, the displacement at the point of maximum tensile-shear load is $0.92 \mathrm{~mm}$. Increasing
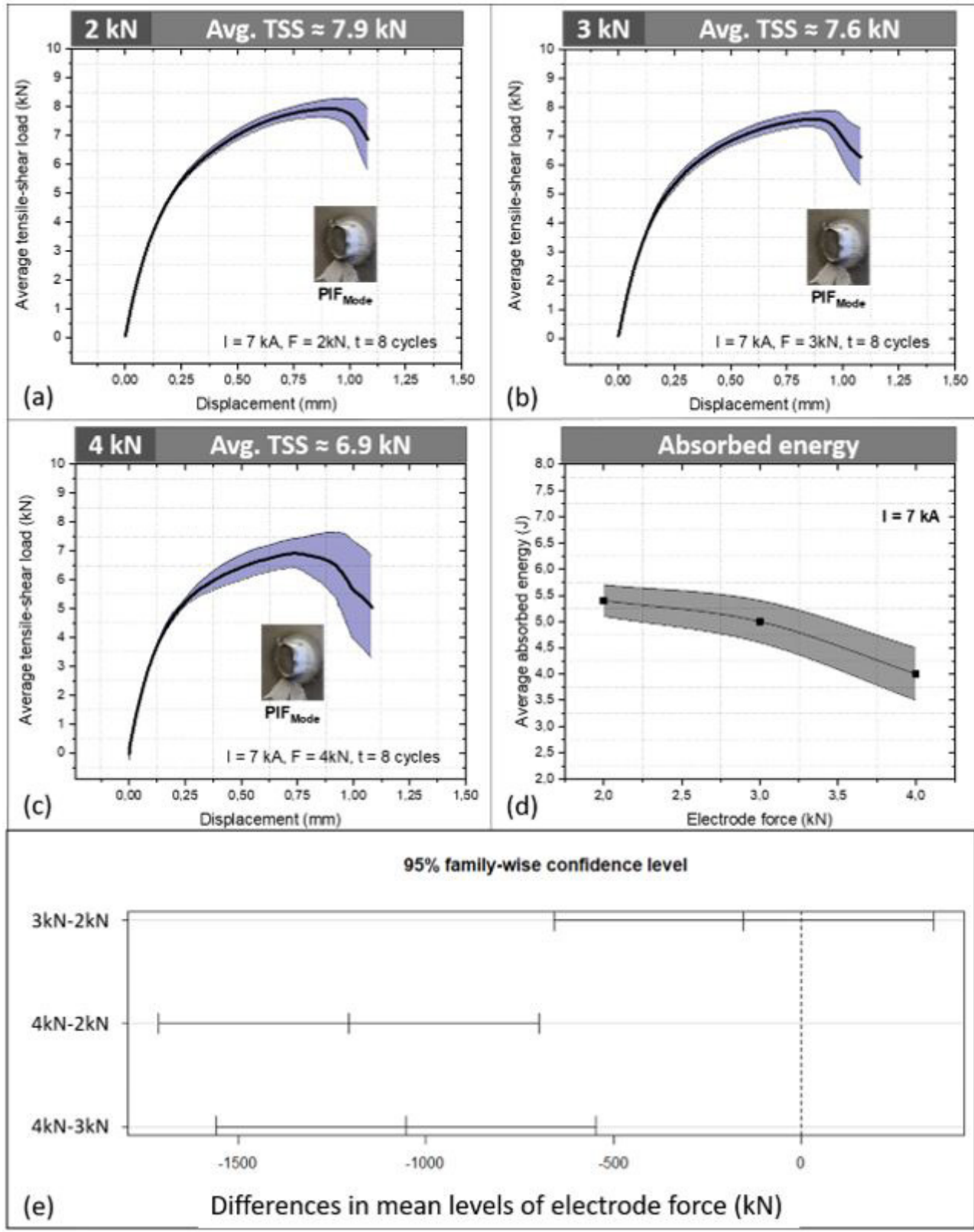

Figure 10. Tensile-shear test results for different electrode compression force values. Welding current $(7 \mathrm{kA})$ and welding time (8 cycles) were kept constant. 
the electrode force from $2 \mathrm{kN}$ to $3 \mathrm{kN}$ represents a decrease from 0.92 to $0.87 \mathrm{~mm}$ in the ductility. When the electrode force applied is $4 \mathrm{kN}$, the displacement at the same point is at the order of $0.75 \mathrm{~mm}$. It is also observable an increase in the standard deviation curves, especially when an electrode force of $4 \mathrm{kN}$ is applied.

Such a decrease in both TSS and displacement implies in a decrease of the energy absorption capability of the weld spots (Figure 10d). The absorbed energy decreases from $5.3 \mathrm{~J}$ to $4.0 \mathrm{~J}$ when the electrode compression force increases from $2 \mathrm{kN}$ to $4 \mathrm{kN}$, respectively. These results suggest that the mechanical stability of the weld spots is more sensible to changes in the electrode compression force when lower heat inputs are applied during the welding process. It also may be an indicative that the adverse effect of the electrode force on the mechanical properties may be compensated by the larger weld spot size when higher welding currents are applied, as demonstrated by Zeytin et al. [11].

Figure 11 shows the effect of the welding time on the quasi-static mechanical strength of the weld spots. It is observable that an increase in welding time produces a pronounced effect in both TSS and energy absorption capability of the weld spots. The average TSS increases from $8.2 \mathrm{kN}$ to $8.7 \mathrm{kN}$ when the welding time is increased from 8 cycles (Figure 11a) to 16 cycles (Figure 11c), although some samples achieved TSS as high as $9.8 \mathrm{kN}$.
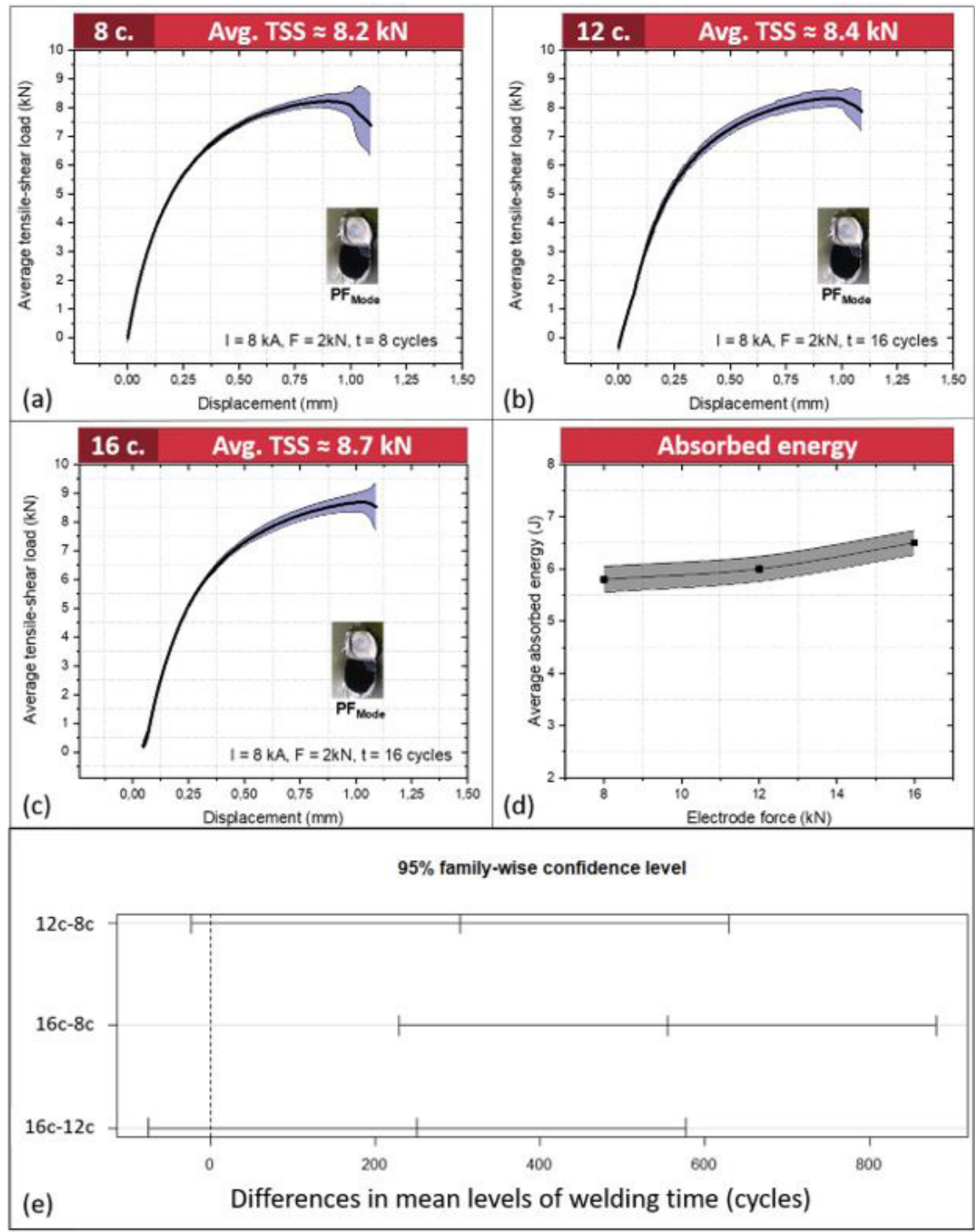

Figure 11. Tensile-shear test results for different welding time values. Welding current $(8 \mathrm{kA})$ and electrode compression force $(2 \mathrm{kN})$ were kept constant. 
Figure 11e shows the Tukey test results for the effect of the welding time. The low ( 8 cycles) and medium (12 cycles) levels of the welding time are not different within a 95\% confidence level. Similar conclusions can be drawn for the difference between the medium and high ( 16 cycles) levels. On the other hand, the low and high levels have different average values, evidencing the effectiveness of the welding time to promote increase in the TSS of the weld spots. The elongation at the maximum TS load also increases from $0.92 \mathrm{~mm}$ to $1.1 \mathrm{~mm}$ (increase of $12 \%$ ) when the welding time increases to 16 cycles. The increase in welding time also promotes a positive effect on the energy absorption capability of the weld spots.

Figure 12 compresses the average tensile-shear strength data obtained from Figure 8 to Figure 11. Based on the observations of the absolute average tensile shear strength values, it is evident that the welding current and the welding time are the most significant welding parameters that influence the load bearing capacity of the TWIP steel weld spots under tensile-shear loading, thereby requiring a tighter control in industrial environments.

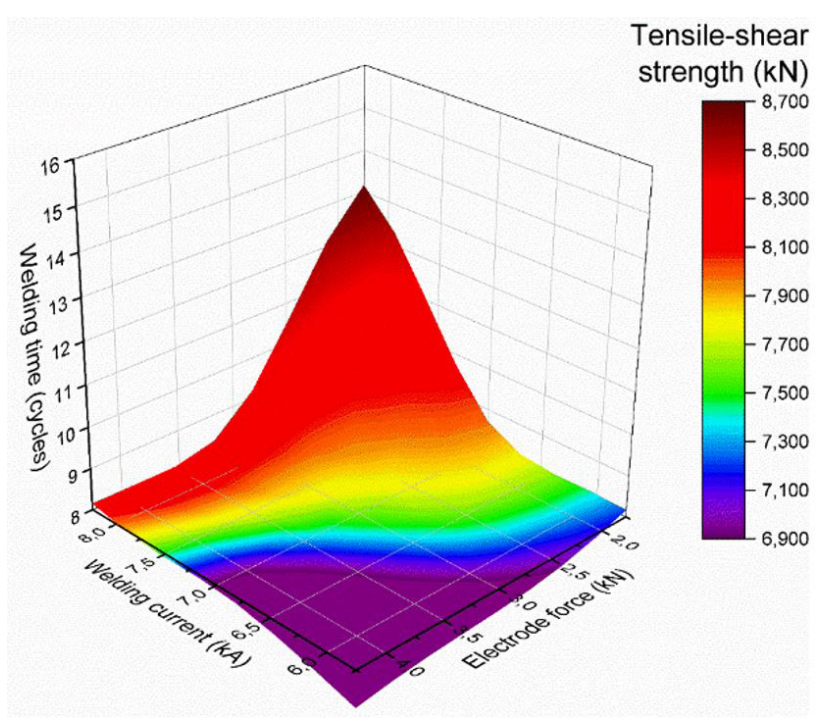

Figure 12. Tridimensional surface plot of the effect of welding parameters on the average tensile-shear strength.

\section{Conclusions}

The following conclusions can be drawn from the results obtained by the experimental investigations conducted in this work:

- The microstructure of the weld spots consisted of a well-defined dendritic $F Z$, a equiaxed-grain HAZ and a narrow PMZ. Grain growth was observed only along a narrow range in the HAZ. The hardness at the FZ showed to be lower than both HAZ and BM. No considerable Mn interdendritic segregation was observed by EDS analysis;

- Tensile-shear loaded weld spots underwent interfacial failure for welding currents up to $6 \mathrm{kA}$. It was confirmed by the cleavage fracture surface evidenced by SEM micrographs. Weld spots with welding currents of $7 \mathrm{kA}$ showed a dominant partial-interfacial failure mode. For welding currents of $8 \mathrm{kA}$, the respective weld spots underwent a dominant pullout failure, when the electrode force is kept fixed as $2 \mathrm{kN}$. It was confirmed by the dimpled fracture surface observed by SEM. Higher electrode compression forces promote a change in failure mode from PF to PIF;

- The load bearing and energy absorption capacities of the weld spots showed to be sensible to the welding parameters. Higher welding current, higher welding time and lower electrode compression force showed to promote the highest tensile-shear strength and energy absorption capability values. These parameters also showed to be correlated to dominant ductile (PF) failure modes. 


\section{Acknowledgements}

The authors would like to thank the Brazilian Federal Agency CAPES for funding this research. Grant number 300886/2013-6.

\section{References}

[1] Beladi H, Timokhina IB, Estrin Y, Kim J, De Cooman BC, Kim SK. Orientation dependence of twinning and strain hardening behaviour of a high manganese twinning induced plasticity steel with polycrystalline structure. Acta Materialia. 2011;59(20):77877799. http://dx.doi.org/10.1016/j.actamat.2011.08.031.

[2] Kim J, Lee SJ, De Cooman BC. Effect of Al on the stacking fault energy of Fe-18Mn-0.6C twinning-induced plasticity. Scripta Materialia. 2011;65(4):363-366. http://dx.doi.org/10.1016/j. scriptamat.2011.05.014.

[3] Chin KG, Kang C-Y, Shin SY, Hong S, Lee S, Kim HS, et al. Effects of Al addition on deformation and fracture mechanisms in two high manganese TWIP steels. Materials Science and Engineering A. 2011;528(6):2922-2928. http://dx.doi.org/10.1016/j. msea.2010.12.085.

[4] De Cooman BC, Kim J, Lee S. Heterogeneous deformation in twinning-induced plasticity steel. Scripta Materialia. 2012;66(12):986991. http://dx.doi.org/10.1016/j.scriptamat.2012.02.028.

[5] Chabok A, van der Aa E, De Hosson JTM, Pei YT. Mechanical behavior and failure mechanism of resistance spot welded DP1000 dual phase steel. Materials \& Design. 2017;124:171182. http://dx.doi.org/10.1016/j.matdes.2017.03.070.

[6] Saha DC, Cho Y, Park Y-D. Metallographic and fracture characteristics of resistance spot welded TWIP steels. Science and Technology of Welding and Joining. 2013;18(8):711-720. http://dx.doi.org/10.1179/1362171813Y.0000000151.

[7] Pouranvari M, Marashi SPH. Failure mode transition in AHSS resistance spot welds. Part I. Controlling factors. Materials Science and Engineering A. 2011;528(29-30):8337-8343. http:// dx.doi.org/10.1016/j.msea.2011.08.017.

[8] RaoSS, Chhibber R, Arora KS, Shome M. Resistance spot welding of galvannealed high strength interstitial free steel. Journal of Materials Processing Technology. 2017;246:252-261. http:// dx.doi.org/10.1016/j.jmatprotec.2017.03.027.

[9] Razmpoosh MHH, Shamanian M, Esmailzadeh M. The microstructural evolution and mechanical properties of resistance spot welded $\mathrm{Fe}-31 \mathrm{Mn}-3 \mathrm{Al}-3 \mathrm{Si}$ TWIP steel. Materials \& Design. 2015;67:571576. http://dx.doi.org/10.1016/j.matdes.2014.10.090.

[10] Russo Spena P, Lombard F, Maddis M, Rossini M. Investigation on resistance spot welding of twip steel sheets. Steel Research International, 86, 1480-1489, 2015. http://dx.doi.org/10.1002/ srin. 201400336.

[11] Kazdal Zeytin H, Ertek Emre, H, Kaçar R. Properties of resistance spot-welded TWIP steels. Metals. 7(1):14, 2017. http://dx.doi. org/10.3390/met7010014.

[12] Saha DC, Chang I, Park Y-D. Heat-affected zone liquidation crack on resistance spot welded TWIP steels. Materials Characterization. 2014;93:40-51. http://dx.doi.org/10.1016/j. matchar.2014.03.016.

[13] Ashiri R, Shamanian M, Salimijazi HR, Haque MA, Bae J-H, Ji $\mathrm{C}-\mathrm{W}$, et al. Liquid metal embrittlement-free welds of Zn-coated twinning induced plasticity steels. Scripta Materialia. 2016;114:4147. http://dx.doi.org/10.1016/j.scriptamat.2015.11.027.

[14] Lorthios J, Mazière M, Lemoine X, Cugy P, Besson J, GourguesLorenzon A-F. Fracture behaviour of a Fe-22Mn-0.6C-0.2V austenitic TWIP steel. International Journal of Mechanical Sciences. 2015;101-102:99-113. http://dx.doi.org/10.1016/j. ijmecsci.2015.07.029.

[15] Sellars C-M, Whiteman J-A. Recrystallization and grain growth in hot rolling. Metal Science. 1979;13:187-94. http://dx.doi. org/10.1179/msc.1979.13.3-4.187.

[16] Zhang H, Senkara J. Resistance welding: fundamentals and applications. 2. ed. Boca Raton: CRC Press; 2011.406 p. http:// dx.doi.org/10.1201/b11752.

[17] Pouranvari M, Marashi SPH. Critical review of automotive steels spot welding: process, structure and properties. Science and Technology of Welding and Joining. 2013;18(5):361-403. http:// dx.doi.org/10.1179/1362171813Y.0000000120.

[18] Yuan X, Li C, Chen J, Li X, Liang X, Pan X. Resistance spot welding of dissimilar DP600 and DC54D steels. Journal of Materials Processing Technology. 2017;239:31-41. http://dx.doi. org/10.1016/j.jmatprotec.2016.08.012.

[19] Jin JE, Lee YK. Effects of Al on microstructure and tensile properties of C-bearing high Mn TWIP steel. Acta Materialia. 2012;60(4):16801688. http://dx.doi.org/10.1016/j.actamat.2011.12.004. 